\title{
Mutagenic Effects of Gamma Radiation on Eight Accessions of Cowpea (Vigna unguículata [L.] Walp.)
}

\author{
Festus Olakunle Olasupo ${ }^{1,2^{*}}$, Christopher Olumuyiwa Ilori' ${ }^{1}$, Brian Peter Forster ${ }^{3}$, \\ Souleymane Bado 4 \\ ${ }^{1}$ Department of Crop Protection and Environmental Biology, University of Ibadan, Ibadan, Nigeria \\ ${ }^{2}$ Plant Breeding Section, Cocoa Research Institute of Nigeria, Ibadan, Nigeria \\ ${ }^{3}$ Biohybrids International Ltd., Reading, UK \\ ${ }^{4}$ Plant Breeding and Genetics Laboratory Joint FAO/IAEA Agriculture and Biotechnology Laboratory, \\ International Atomic Energy Agency Laboratories, Seibersdorf, Austria \\ Email: *festusolasupo@gmail.com
}

Received 7 January 2016; accepted 23 February 2016; published 26 February 2016

Copyright (C) 2016 by authors and Scientific Research Publishing Inc.

This work is licensed under the Creative Commons Attribution International License (CC BY). http://creativecommons.org/licenses/by/4.0/

(c) (i) Open Access

\section{Abstract}

Mutagenesis is used for creating new genetic variability in cultivar improvement. Optimal mutagenic treatment is required for effective mutation induction in crop species. Therefore, radiosensitivity of cowpea accessions to gamma irradiation was investigated. Seeds of eight cowpea accessions were irradiated with ${ }^{60} \mathrm{Co}$ gamma radiation doses of 100, 200, 300, 400 and $500 \mathrm{~Gy}$. The seeds were sown in pots to evaluate the treatment effects on seed germination (SG), seedling survival (SS) and growth habits of $M_{1}$ generation. Data were analyzed using descriptive statistics. Low rates of SG (10\% - 45\%) were recorded at higher doses (500 - $400 \mathrm{~Gy})$ in Ife Brown (IB) and its derivatives, whereas high SG rates (74\% - 94\%) were observed in IT90K-284-2 across all treatments. Percentage $S S$ was inversely related to gamma dosage. A wide range of $L_{50}$ for $S G$ ( 329 - $1054 \mathrm{~Gy}$ ) and SS (149 - $620 \mathrm{~Gy}$ ) were observed across the cowpea accessions. Low $\mathrm{LD}_{50}$ Scores for SG (329 $516 \mathrm{~Gy}$ ) and SS (149 - $357 \mathrm{~Gy}$ ) were observed among cowpea with rough seed coat, whereas cowpea with smooth seed coat recorded higher $L D_{50}$ for SG (521 and $1054 \mathrm{~Gy}$ ) and SS (449 and $620 \mathrm{~Gy}$ ). Seed germination $L D_{50}$ and $S S L D_{50}$ were highly correlated with mean coat thickness $(0.899$ and $0.937)$ than mean seed weight $(0.621$ and 0.678$)$. Gamma irradiation of cowpea seed at low dosage (100 Gy) increased the vigor of $M_{1}$ seedlings with respect to primary leaf area, terminal leaflet area, seedling height and plant height at six weeks. Doses of $200 \mathrm{~Gy}$ and above resulted in a progressive reduction in vigor of plant and seed setting of cowpea. Radio-sensitivity varied with cowpea genotype and was associated with seed testa texture, thickness and seed weight. Low gamma

"Corresponding author.

How to cite this paper: Olasupo, F.O., Ilori, C.O., Forster, B.P. and Bado, S. (2016) Mutagenic Effects of Gamma Radiation on Eight Accessions of Cowpea (Vigna unguiculata [L.] Walp.). American Journal of Plant Sciences, 7, 339-351.

http://dx.doi.org/10.4236/ajps.2016.72034 
irradiation treatment (100 Gy) may be used to enhance seedling vigor, vegetative growth and yield of cowpea at $M_{1}$ generation.

\title{
Keywords
}

\author{
Cowpea, Mutagenesis, Radio-Sensitivity, Gamma Irradiation, Optimum Mutation Treatment
}

\section{Introduction}

Cowpea (Vigna unguiculata) is emerging as a valuable crop for dry regions in tropical and sub-tropical regions. It is a leguminous crop, providing a sustainable source of protein for human and animal nutrition [1]. It is a native of southern Africa, but has spread to cover over 65 countries worldwide [1] of which Nigeria, Niger, Senegal, Ghana, Mali and Burkina Faso are the principal producing countries. In addition to providing a cheap source of protein, it is also a good source of carbohydrate, minerals (potassium, phosphorus, calcium, iron, copper, zinc and boron), vitamins and carotene [2] [3].

Cowpea has an estimated global production area of over 14.5 million hectares [4] and its annual grain production has increased to over 6.3 million metric tons in 2008 [1] due to concerted research efforts that has led to the release of improved cowpea varieties to farmers in producing countries. Nigeria is the number one world producer of cowpea with an annual production of 2,950,000 MT in 2013 [4]. However, cowpea productivity and production in Nigeria has major constraints. These include devastating diseases and insect pests, a narrow genetic base for breeding, poor cultural practices and a low product quality [5]. Abiotic stresses such as low $\mathrm{pH}$, low fertility, excessively high temperatures, drought and inadequate crop protection practices also limit production. Some recent achievements in yield increase and product quality improvement have been attributed to combined efforts of scientists affiliated with the International Institute of Tropical Agriculture (IITA), the Dry Grain Pulses Collaborative Research Support Program (CRSP), Purdue Improved Cowpea Storage (PICS) and from national programs [6].

The primary objective of the plant breeder is to produce crops that perform better, usually in terms of yield and quality, than existing cultivars and this is dependent on the availability of genetic variation, preferably in the primary gene pool. Where genetic diversity is insufficient, new material needs to be accessed or new variation created through induced mutation. Mutation induction has become an established tool in plant breeding to supplement existing germplasm and to improve cultivars in certain specific traits. The first mutant cultivar was produced in tobacco in Indonesia in 1936 and up to the recent time, 3220 cultivars in over 220 crop species have been developed and released to farmers all over the world [7]. However, little work has been reported on mutation breeding in cowpea [8]-[10], which has been widely used among other legume crops. An exception is India where 10 cowpea mutant cultivars have been released to farmers [11].

Mutagenesis in plants can be achieved by using physical agents (ionizing and non-ionizing radiations) or chemical mutagens. However, several practical problems with chemical mutagens have been identified, which include soaking of seeds, penetration of the relevant target cells, safety of handling and disposal among many others [12]. Among the radiation-based methods, gamma-ray and fast neutron bombardment now supersedes $\mathrm{X}$-ray in most applications. Of these, gamma irradiation is known to be the most effective in inducing a wide range of mutations [7]. Gamma-rays penetrate deeply into target tissues than other radiations [13] and it is less destructive, whereas fast neutron bombardment causes translocations, chromosome losses and large deletions [14]. It is an electromagnetic radiation with short wavelength which has the tendency to dislodge an electron from its orbit around the nucleus, thereby producing an ion as the corresponding proton becomes positively charged and release energy (ionization or ion pairs) as its passes through a tissue. The principal effect of ionizing radiation is the ionization of water, which forms highly reactive hydroxyl radicals [15]. These radical react with cellular components, especially DNA to cause mutations.

The first step in mutation breeding is to select the genotypes for improvement (mutation induction). These are usually the medium performing cultivars and elite genotypes to be improved. The next step is to determine the optimal mutation treatment. This is done by radio-sensitivity testing [16] of the target genotype(s) as responses vary between species and genotypes. Therefore, the aim of the current study was to determine optimal mutation induction treatments using gamma irradiation for a range of selected cowpea accessions in Nigeria. 


\section{Materials and Methods}

\subsection{Plant Material and Seed Production for Mutagenesis}

Eight cowpea accessions were selected for this study and these varied for a number of traits as listed in Table 1. The cultivar IB and its mutant derivatives (IB-Y-1, IB-CR and IB-BPC) were chosen because of their average yield performance and brown seed color which is highly desirable by cowpea consumers in Nigeria, while the four elite cultivars were selected for their good yield and distinguishing characteristics (Table 1). IB and its derivatives were collected from the Genetics Unit of the Department of Crop Protection and Environmental Biology (DCPEB), University of Ibadan (UI), Nigeria, while the four elite cultivars were obtained from the Genetic Resources Centre of the International Institute of Tropical Agriculture (IITA), Ibadan, Nigeria.

All seed used for this study were produced from plants raised the roof top garden of DCPEB, UI, Ibadan, Nigeria. The seeds of each cowpea genotype were planted in pots filled with garden soil and grown on to multiply seeds for radio-sensitivity testing. Seedlings were thinned to one plant per pot two weeks after planting. The plants were watered daily and weeding of the pots was carried out as soon as weeds were observed. Insect pests were controlled by spraying with Cyper-DiForce ${ }^{\mathrm{R}}$ two weeks after emergence and every ten days afterwards, Z-Force ${ }^{\mathrm{R}}$ was used as a fungicide when necessary. At maturity, dried seeds of each accession were harvested, place into envelopes, labeled appropriately and store $4^{\circ} \mathrm{C}$. Seed viability was carried out by conducting germination tests.

\subsection{Cowpea Mutagenesis Using Gamma Irradiation}

Batches of dried seeds of the eight cowpea accessions were shipped to the Plant Breeding and Genetics Laboratory of International Atomic Energy Agency, Seibersdorf, Austria for gamma irradiation ( ${ }^{60}$ Co) using a Gamma Cell with an activity of $202 \mathrm{~Gy} / \mathrm{min}$. Prior to irradiation the seeds were maintained in desiccators for at least 3 days to equilibrate seed moisture to $12 \%-14 \%$. The 8 cowpea accessions were treated with irradiation doses of 0 , 100, 200, 300, 400 and $500 \mathrm{~Gy}$ using at least 150 seeds per dosage. Irradiated seeds $\left(\mathrm{M}_{1}\right)$ were returned to DCPEB for testing. Seeds from each treatment (Table 2) were used to raise $\mathrm{M}_{1}$ plants at the rooftop garden of DCPEB. The seeds were sown in 5 liter plastic pots and polyethylene bags filled with top soil at the rate of 4 seeds per pot. Plants from each treatment were arranged together in rows. The radio-sensitivity test was maintained by appropriate cultural operations as stated earlier in the seed production.

\begin{tabular}{|c|c|c|c|c|c|c|c|c|c|c|c|}
\hline $\begin{array}{c}\text { Cowpea } \\
\text { accession }\end{array}$ & Source & Plant type & $\begin{array}{c}\text { Terminal } \\
\text { leaflet shape }\end{array}$ & $\begin{array}{c}\text { Leaf } \\
\text { colour }\end{array}$ & $\begin{array}{l}\text { Peduncle } \\
\text { type }\end{array}$ & $\begin{array}{c}\text { Leaf } \\
\text { texture }\end{array}$ & $\begin{array}{c}\text { Flower } \\
\text { colour } \\
\text { code }\end{array}$ & $\begin{array}{c}\text { Pod } \\
\text { anthocyanin } \\
\text { pigmentation }\end{array}$ & $\begin{array}{l}\text { Seed } \\
\text { colour }\end{array}$ & $\begin{array}{c}\text { Seed } \\
\text { texture }\end{array}$ & Use \\
\hline IB (Ife Brown) & UI, Nigeria & Semi-erect & Subglobose & Green & $\begin{array}{c}\text { Not } \\
\text { branched }\end{array}$ & Smooth & 2 & None & Brown & Rough & Cultivar \\
\hline IB-Y-1 & UI, Nigeria & Semi-erect & Subglobose & Yellow & $\begin{array}{c}\text { Not } \\
\text { branched }\end{array}$ & Smooth & 2 & None & Brown & Rough & Mutant of IB \\
\hline IB-BPC & UI, Nigeria & Semi-erect & Subglobose & Green & Branched & Smooth & 2 & None & Brown & Rough & $\begin{array}{l}\text { Mutant of } \\
\text { IB/Variety }\end{array}$ \\
\hline IB-CR & UI, Nigeria & Semi-erect & Subglobose & Green & $\begin{array}{c}\text { Not } \\
\text { branched }\end{array}$ & Crinkle & 2 & None & Brown & Rough & Mutant of IB \\
\hline IT86D-719 & IITA, Nigeria & Semi-erect & Subglobose & Green & $\begin{array}{c}\text { Not } \\
\text { branched }\end{array}$ & Smooth & 1 & Whole pod & White & Rough & Elite cultivar \\
\hline IT86D-1010 & IITA, Nigeria & Semi-erect & Hastate & Green & $\begin{array}{c}\text { Not } \\
\text { branched }\end{array}$ & Smooth & 2 & Tip only & White & Smooth & Elite cultivar \\
\hline IT89KD-374-57 & IITA, Nigeria & emi-spreading & Subglobose & Green & $\begin{array}{c}\text { Not } \\
\text { branched }\end{array}$ & Smooth & 3 & None & Cream & Rough & Elite cultivar \\
\hline IT90K-284-2 & IITA, Nigeria & Semi-erect & Subglobose & Green & $\begin{array}{c}\text { Not } \\
\text { branched }\end{array}$ & Smooth & 4 & None & Tan & Smooth & Elite cultivar \\
\hline
\end{tabular}

Flower Pigmentation Code: 1 = None; 2 = Wing is pigmented; 3 = Wing is pigmented, standard petal is partially pigmented with light base; 4 = Wing is deeply pigmented, standard is pigmented with V-shaped light base; 5 = Completely pigmented. 
Table 2. Number of gamma irradiated cowpea seeds sown at $\mathrm{M}_{1}$ for each accession.

\begin{tabular}{cccccccc}
\hline & \multicolumn{7}{c}{ Treatment dose (Gy) } \\
\cline { 2 - 7 } Accession & 0 & 100 & 200 & 300 & 400 & 500 \\
IB & 150 & 170 & 178 & 175 & 182 & 181 \\
IB-Y-1 & 150 & 200 & 186 & 190 & 190 & 190 & 190 \\
IB-BPC & 150 & 194 & 194 & 193 & 194 & 167 & 167 \\
IB-CR & 150 & 165 & 165 & 167 & 187 & 200 \\
IT86D-719 & 200 & 175 & 190 & 182 & 200 & 200 \\
IT86D-1010 & 200 & 200 & 200 & 200 & 200 & 200 \\
IT89KD-374-57 & 200 & 200 & 200 & 200 & 200 & 200 & 200 \\
IT90K-284-2 & 200 & 191 & 200 & 200 & & \\
\hline
\end{tabular}

The numbers vary because of lost due to the shipment condition Nigeria-Austria for irradiation service.

\subsection{Data Collection and Analysis}

Observations were made on plant morphology such as: primary leaf area, seedling height at 3 weeks after sowing; terminal leaflet area, plant height at 6 weeks after planting and seed setting at maturity.

The data taken were used to calculate germination rates and seedling survival for each treatment as follows:

$$
\begin{aligned}
& \% \text { Germination }=\frac{\text { No of germinated seeds }}{\text { No of irradiated seeds planted }} \times 100 \\
& \% \text { Seedling survival }=\frac{\text { No of survived seedlings }}{\text { No of germinated seeds }} \times 100
\end{aligned}
$$

The difference in seedling survival was expressed as percentages of control using the equation:

$$
S=\frac{[\text { Seedling survival }]_{\mathrm{Tr}}}{[\text { Seedling survival }]_{\mathrm{Co}}} \times 100
$$

where: $S=\%$ difference in seedling survival, $\mathrm{Tr}=$ Treatment and Co = Control.

Absorbed doses were plotted against the percentage differences in seedling survival (Dosage Effect Curve) for each accession to assess the damage due to gamma irradiation. By inserting the "line of best fit" a reading corresponding to 50\% reduction could be obtained. Data taken on morpho-agronomic traits were analyzed using SAS (Statistical Analysis System, version 9.0) software using the general linear model procedure (PROC GLM). The estimation of the $\mathrm{M}_{2}$ generation is based on the optimal dose for mutation induction, this is usually in the range $\mathrm{LD}_{30-50}$, and was estimated using the seedling survival and seed set data.

\section{Results}

\subsection{Radio-Sensitivity}

Gamma irradiation affected the germination of all cowpea accessions and was most lethal for Ife Brown and its derivatives at 500 and 400Gy with germination rates ranging from 10\% - 45\%, whereas three of the elite cultivars (IT86D-719, IT86D-1010 and IT89KD-374-57) showed some resistance to gamma irradiation, having a range of 35\% - 67\% germination at 500 and $400 \mathrm{~Gy}$. IT90K-284-2 was the most tolerant accession to gamma irradiation by exhibiting high germination range (74\% - 94\%) across the radiation treatments. In all the cowpea accessions, 62\% - 85\% germination were observed at 300Gy treatments. The SG percentage at 200 Gy was significantly lower than the control treatment in five accessions, but not in IB, IB-BPC and IT90K-284-2. No significant difference was observed between the percentage germination at $100 \mathrm{~Gy}$ and control treatments in all the cowpea accessions except in IT86D-719 and IT89KD-374-57 (Figure 1). 


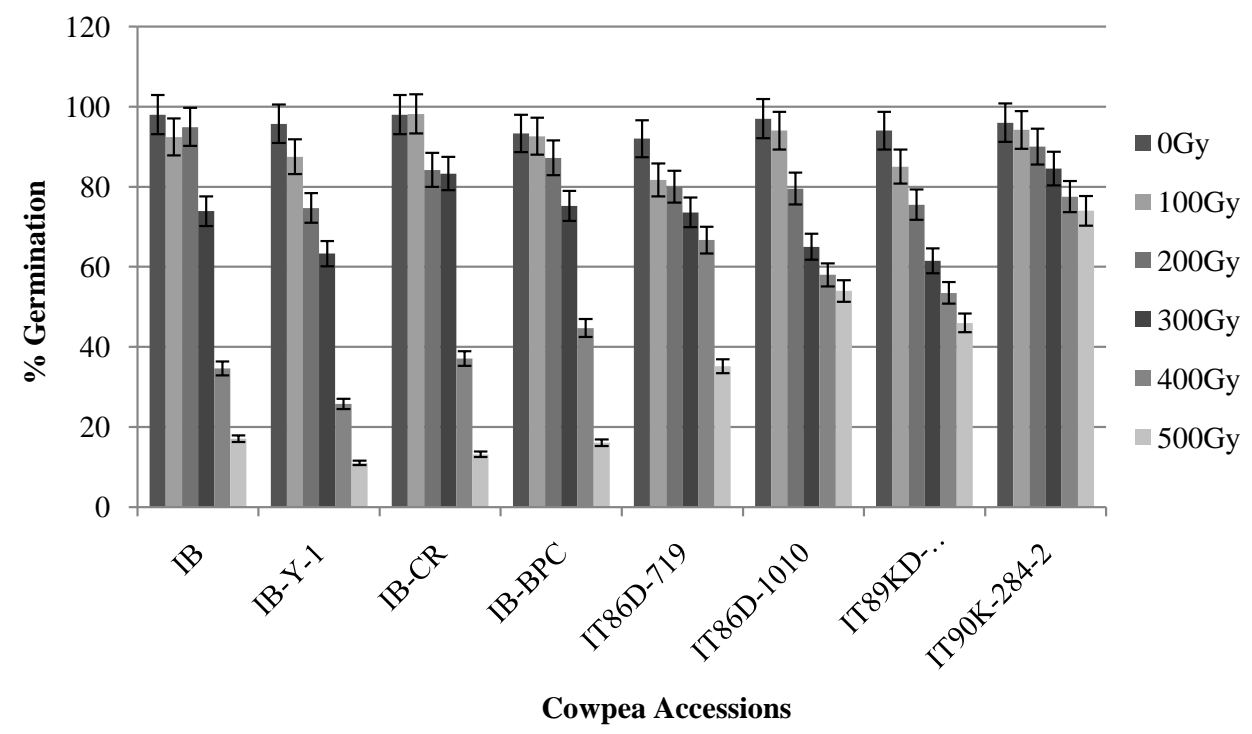

Figure 1. Effect of gamma rays on cowpea seed germination in the $\mathrm{M}_{1}$ generation.

\subsection{Effect of Gamma Irradiation on Cowpea $\mathrm{M}_{1}$ Seedling Survival}

The results of cowpea SS ( $\mathrm{M}_{1}$ generation) are presented in Figure 2. A trend similar to that observed for germination percentage was observed. No SS was recorded at $500 \mathrm{~Gy}, 400 \mathrm{~Gy}$ and $300 \mathrm{~Gy}$ in IB and IB-Y1. In IB-CR and IB-BPC fewer than 5\% seedlings survived at $300 \mathrm{~Gy}$. These indicate that IB and its derivatives are more susceptible to gamma radiation than the elite cultivars. Lower percentage SS (<65\%) at $500 \mathrm{~Gy}, 400 \mathrm{~Gy}$ and 300 Gy was observed in IT86D-719, IT86D-1010 and IT89KD-374-57, whereas in IT90K-284-2 80\% SS was recorded at $300 \mathrm{~Gy}$. No significant difference was observed in the percentage SS of IT90K-284-2 at 200, 100 Gy and the control treatment. The percentage SS recorded for 5 out of the 8 cowpea accessions was significantly different at $100 \mathrm{~Gy}$ from the control treatment, but not for IB-CR, IT86D-1010 and IT90K-284-2.

\subsection{Effect of Seed Characteristics on Cowpea Radio-Sensitivity}

The gamma irradiation response curves for SG and SS of the 8 cowpea accessions are presented in Figure 3 and Figure 4, while the $\mathrm{LD}_{50}$ for $\mathrm{SG}$ and $\mathrm{SS}$ as inferred from the radiation effect curves are presented in Table 3. The rates of SG and SS reduced as gamma radiation dosage increased in IB and its derivatives. A similar trend was also observed among the 4 elite cowpea cultivars, but more gradually.

A wide variation in the estimated $\mathrm{LD}_{50}$ was observed among the 8 cowpea accession. The lowest $\mathrm{LD}_{50}$ scores, for seed germination (326 Gy) and seedling survival (148.8 Gy), were recorded for IB-Y-1, while IT90K-284-2 recorded the highest $\mathrm{LD}_{50}$ for SG (1053.6 Gy) and SS (620.2 Gy). Generally, lower values of $\mathrm{LD}_{50}$ were observed for IB and its derivatives, which range from 363.9 Gy and 389.1 Gy for SG and 148.8 Gy to 198.8 Gy for SS. The relationship between seed characteristics and relative susceptibility of cowpea genotypes to gamma irradiation is presented in Table 3. Cowpea accessions with a smooth testa (seed coat) surface (IT86D-1010 and IT90K-284-2) recorded higher values of SG LD 50 (520.5 Gy and 1053.6 Gy) and SS LD $\mathrm{L}_{50}$ (449.4 Gy and 620.2 Gy) than the accessions with rough seed coat (IB, IB-Y-1, IB-CR, IB-BPC, IT86D-719 and IT89KD-374-57).

Thick seed testa $(0.32 \mathrm{~mm})$ corresponded to the high $\mathrm{LD}_{50}$ scores (1053.6Gy and 620.2Gy) for germination and SS (respectively) were observed in IT90K-284-2. The cultivar IB-Y-1 which has the thinnest testa (0.11 $\mathrm{mm}$ ), correspondingly recorded the lowest $\mathrm{LD}_{50}$ scores (329 Gy and $148.8 \mathrm{~Gy}$ ) for SG and SS. Although IT90K-284-2 had the highest seed weight ( $0.19 \mathrm{~g}$ ) with corresponding highest $\mathrm{LD}_{50}$ scores (1053.6 Gy and 620.2 Gy), the second highest seed weight observed in IT89KD-374-57 (0.17 g) did not correspond to low $\mathrm{LD}_{50} \mathrm{~S}$ (473.6 Gy and 392 Gy). Similarly, IB, IB-BPC and IT86D-719 had relatively equal seed weights (0.15 g), but varied for $\mathrm{LD}_{50}$ scores. Cowpea accessions with rough testa surface and thin testa were observed to be more radio-sensitive to gamma irradiation. In general, the responses to gamma irradiation on cowpea SG and SS were better correlated with mean testa thickness than seed weight. 


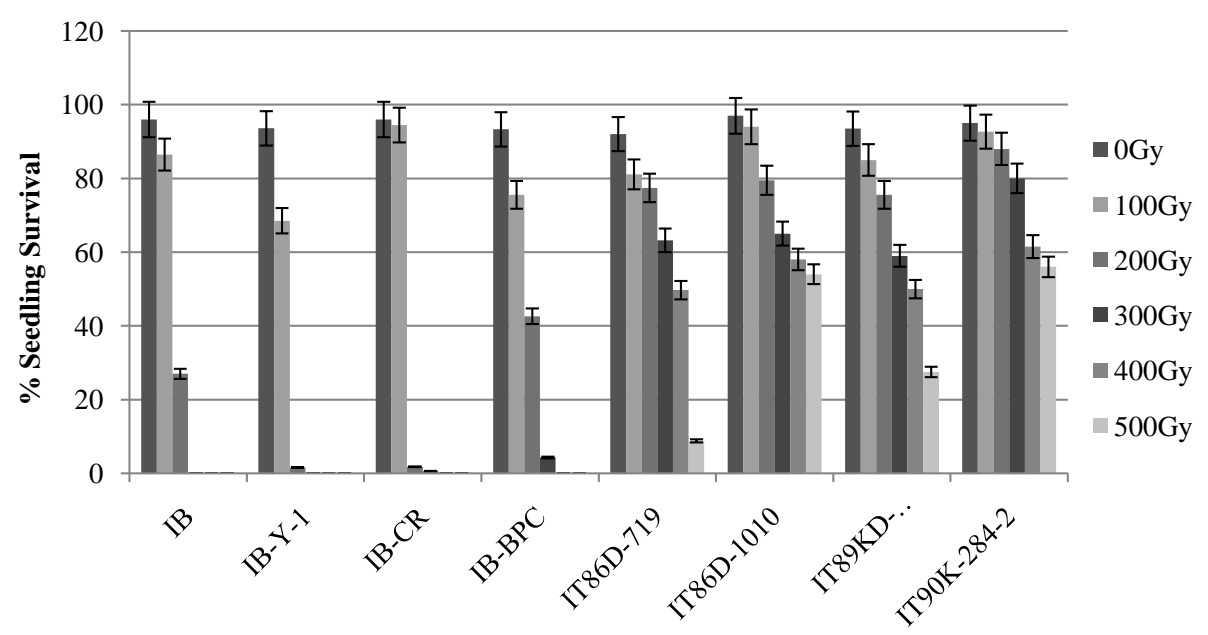

Cowpea Accession

Figure 2. Effect of gamma rays on cowpea seedling survival at $\mathrm{M}_{1}$ generation.

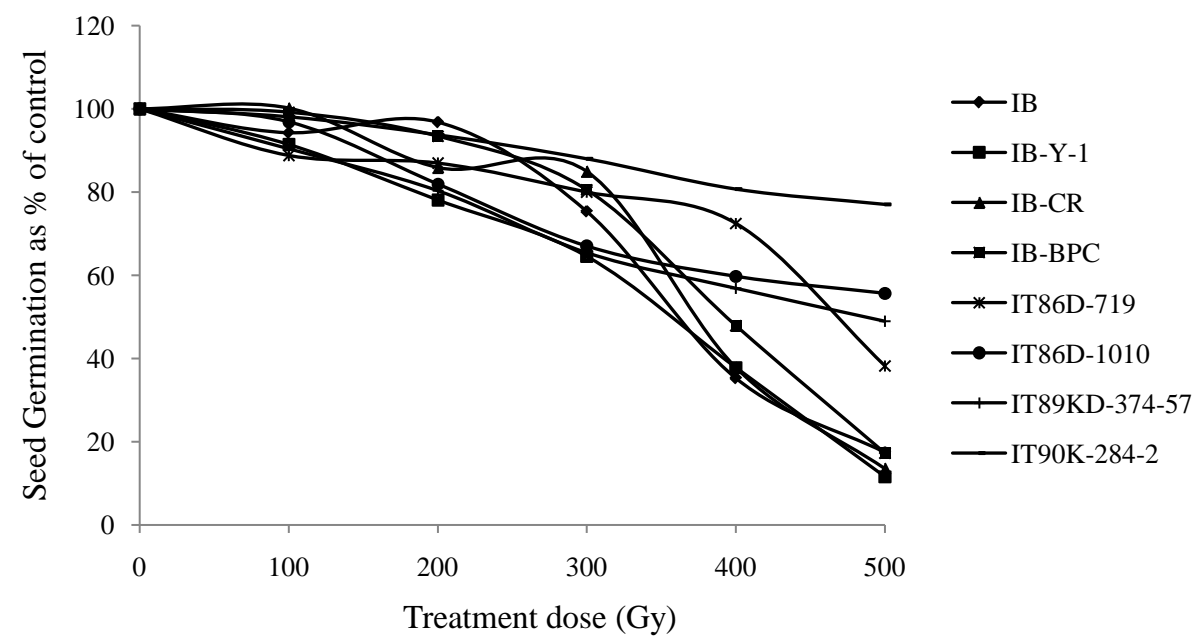

Figure 3. Percentage reduction in the germination of seeds exposed to gamma radiation (compared with germination from untreated seeds), plotted against gamma irradiation dosage.

Table 3. Effect of seed characteristics on radio-sensitivity, ranked by $\mathrm{LD}_{50}$ scores.

\begin{tabular}{cccccc}
\hline Cowpea accession & Seed coat texture & Mean coat thickness $(\mathrm{mm})$ & Mean seed weight $(\mathrm{g})$ & SG LD $_{50}(\mathrm{~Gy})$ & SS LD \\
50 & $(\mathrm{Gy})$ \\
\hline IB-Y-1 & Rough & $0.11 \pm 6.3246 \times 10^{-4}$ & $0.11 \pm 3.2945 \times 10^{-4}$ & 329.0 & 148.8 \\
IB & Rough & $0.12 \pm 6.8718 \times 10^{-4}$ & $0.15 \pm 3.7884 \times 10^{-4}$ & 363.9 & 190.3 \\
IB-CR & Rough & $0.11 \pm 9.6667 \times 10^{-4}$ & $0.14 \pm 5.2872 \times 10^{-3}$ & 365.1 & 177.5 \\
IB-BPC & Rough & $0.12 \pm 7.6085 \times 10^{-4}$ & $0.15 \pm 2.1492 \times 10^{-4}$ & 389.1 & 198.8 \\
IT89KD-374-57 & Rough & $0.18 \pm 6.3596 \times 10^{-4}$ & $0.17 \pm 5.1953 \times 10^{-4}$ & 473.6 & 392.0 \\
IT86D-719 & Rough & $0.15 \pm 9.4281 \times 10^{-4}$ & $0.15 \pm 2.5382 \times 10^{-4}$ & 516.2 & 357.1 \\
IT86D-1010 & Smooth & $0.22 \pm 6.5320 \times 10^{-4}$ & $0.16 \pm 7.4559 \times 10^{-4}$ & 520.5 & 449.4 \\
IT90K-284-2 & Smooth & $0.32 \pm 7.4907 \times 10^{-4}$ & $0.19 \pm 8.4539 \times 10^{-4}$ & 1053.6 & 620.2 \\
\hline
\end{tabular}

SG = Seed germination; $S S=$ Seedling survival: $S G L_{50}$ and $S S$ LD 50 are highly correlated with mean coat thickness (0.899 and 0.937$)$ than mean seed weight (0.621 and 0.678). 


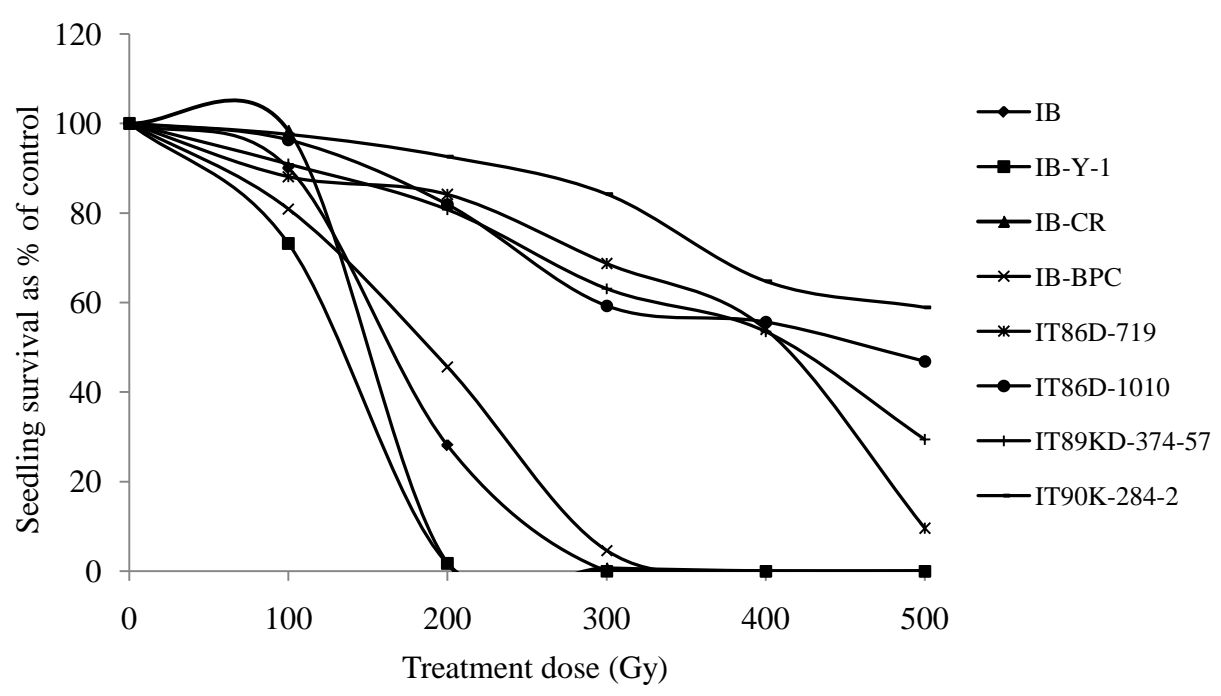

Figure 4. Percentage reduction in seedling survival of $\mathrm{M}_{1}$ generation following seeds exposed to gamma radiation (compared with seedling survival from untreated seeds), plotted against gamma irradiation dosage.

\subsection{Effects of Gamma Irradiation on $\mathbf{M}_{1}$ Plant Biomass}

The highest coefficient of variation (CV) values (64.3\%, 51.49\%, 59.31\%, 67.11\%, 55.82\%, 54.09\%, 56.51\% and $63.44 \%$ ) were recorded for primary leaf area among the four growth habits and yield parameter studied ranging from $51.49 \%$ to $67.11 \%$ respectively for IB-Y-1, IB-CR, IB-BPC (Table 4(a) \& Table 4(b)). The primary leaf area at 100Gy was higher than control treatments in all the accessions except in IB, IB-CR and IT86D-1010. In all the cowpea accessions, primary leaf area reduced progressively with increasing gamma irradiation dose (from 200 Gy upward) with the lowest value of primary leaf area observed at 500 Gy in all the accessions studied.

Gamma irradiation with the dose range 100 to 500 Gy showed no significant effects on the terminal leaflet area of all the cowpea accessions except IB and IB-Y-1. The terminal leaflet area of IB and IB-Y-1 at 100 and 200 Gy was larger than the control treatments (Table 4(a) \& Table 4(b)). In this study increasing doses of gamma rays progressively inhibited the seedling height for all cowpea accessions. $100 \mathrm{~Gy}$ of gamma irradiation enhanced the seedling height in comparison to the untreated in all the accessions (Table 4(a) \& Table 4(b)).

A similar trend of the effects of gamma irradiation on seedling height was observed for plant height at 6 weeks. At $100 \mathrm{~Gy}$, plant height was greater than the control treatment in all cowpea accessions. From $200 \mathrm{~Gy}$ to 500 Gy, plant height reduced progressively with the shortest plants observed at 500 Gy (Table 4(a) \& Table 4(b)). These results show that low dosage (100 Gy) of gamma irradiation enhanced vegetative growth of cowpea at $\mathrm{M}_{1}$ generation.

Generally the mean seed set per plant at $\mathrm{M}_{1}$ generation decreased with increasing radiation dosage. The highest mean seed set per plant was observed in IB (46) and IB-CR (47) at 100 Gy. Seed set per plant at 100 Gy irradiation was higher than that recorded for the control treatment in all the cowpea genotypes. This indicates that irradiation of cowpea seed by gamma rays at $100 \mathrm{~Gy}$ increases the yield of $\mathrm{M}_{1}$ plants, while treatment levels above $100 \mathrm{~Gy}$ reduced yield of $\mathrm{M}_{1}$ plants. Thus less than 1000 produced seeds were by IB and its derivatives at 200 and 300 Gy and elite cultivars with gamma irradiation above 400 Gy (Table 4(a) \& Table 4(b)). The estimated $\mathrm{M}_{2}$ seed base on the minimum recommended amount of seed for $\mathrm{M}_{1}$ (i.e. 1000) and survival rate showed that IB and its derivatives will produce higher amount $\mathrm{M}_{2}$ seed (between 10,000 - 25,000) compared to elite cultivars (between 1500 - 14,000) as shown in Table 5.

\section{Discussion}

The process of exposing living organisms to physical or chemical agents for the purpose of inducing mutation is referred to as mutagenesis. This process may produce immediate effects such as physiological disturbance on the organism and induced mutations which can be transmitted to subsequent generations [17]. The results of 
Table 4. (a) Effects of gamma radiation on four growth habit traits of cowpea cultivar Ife Brown and its derivatives in the $\mathrm{M}_{1}$ generation; (b) effects of gamma radiation on four growth habit traits of elite cowpea cultivars in the $\mathrm{M}_{1}$ generation.

(a)

\begin{tabular}{|c|c|c|c|c|c|c|c|}
\hline Cowpea accession & Treatment dose (Gy) & PRLA $\left(\mathrm{cm}^{2}\right)$ & TLA $\left(\mathrm{cm}^{2}\right)$ & SDLH (cm) & PLHSW (cm) & MSSPP & AMSS \\
\hline \multirow[t]{6}{*}{ IB } & 0 & $25.90 \pm 0.18$ & $50.16 \pm 3.62$ & $13.04 \pm 0.53$ & $18.84 \pm 0.06$ & $43 \pm 4$ & 3054 \\
\hline & 100 & $20.56 \pm 1.03$ & $62.58 \pm 2.55$ & $13.24 \pm 0.48$ & $21.94 \pm 0.46$ & $46 \pm 2$ & 3866 \\
\hline & 200 & $6.08 \pm 0.48$ & $58.35 \pm 3.23$ & $7.03 \pm 0.65$ & $14.21 \pm 1.42$ & $18 \pm 5$ & 1004 \\
\hline & 300 & NS & NS & NS & NS & NS & NS \\
\hline & 400 & NS & NS & NS & NS & NS & NS \\
\hline & 500 & NS & NS & NS & NS & NS & NS \\
\hline SD & & 9.88 & 10.54 & 3.39 & 4.30 & 16.23 & \\
\hline $\mathrm{CV}$ & & 64.30 & 18.76 & 30.57 & 23.45 & 38.17 & \\
\hline \multirow[t]{6}{*}{ IB-Y-1 } & 0 & $20.13 \pm 1.51$ & $59.86 \pm 3.46$ & $9.40 \pm 0.35$ & $12.41 \pm 0.42$ & $36 \pm 5$ & 1690 \\
\hline & 100 & $22.40 \pm 1.04$ & $66.02 \pm 2.41$ & $10.08 \pm 0.18$ & $16.57 \pm 0.71$ & $38 \pm 3$ & 1695 \\
\hline & 200 & $5.63 \pm 0.53$ & $64.25 \pm 8.60$ & $5.73 \pm 0.23$ & $8.87 \pm 0.34$ & $15 \pm 6$ & 264 \\
\hline & 300 & NS & NS & NS & NS & NS & NS \\
\hline & 400 & NS & NS & NS & NS & NS & NS \\
\hline & 500 & NS & NS & NS & NS & NS & NS \\
\hline SD & & 8.28 & 10.08 & 1.76 & 3.24 & 13.82 & \\
\hline $\mathrm{CV}$ & & 51.49 & 15.97 & 19.36 & 23.52 & 46.29 & \\
\hline \multirow[t]{6}{*}{ IB-CR } & 0 & $16.45 \pm 0.77$ & $33.75 \pm 3.45$ & $13.37 \pm 0.46$ & $18.85 \pm 0.73$ & $44 \pm 7$ & 3785 \\
\hline & 100 & $14.42 \pm 0.72$ & $34.79 \pm 3.16$ & $13.96 \pm 0.44$ & $20.11 \pm 0.58$ & $47 \pm 4$ & 3926 \\
\hline & 200 & $4.48 \pm 0.35$ & $34.70 \pm 7.57$ & $6.47 \pm 0.55$ & $10.53 \pm 0.78$ & $17 \pm 5$ & 259 \\
\hline & 300 & $2.45 \pm 0.36$ & $31.07 \pm 0.00$ & $5.3 \pm 0.00$ & $9.50 \pm 0.00$ & $13 \pm 6$ & 98 \\
\hline & 400 & NS & NS & NS & NS & NS & NS \\
\hline & 500 & NS & NS & NS & NS & NS & NS \\
\hline SD & & 6.20 & 10.07 & 3.15 & 4.02 & 10.08 & \\
\hline $\mathrm{CV}$ & & 59.31 & 29.45 & 25.36 & 22.42 & 43.15 & \\
\hline \multirow[t]{6}{*}{ IB-BPC } & 0 & $24.98 \pm 0.94$ & $56.43 \pm 3.26$ & $11.89 \pm 0.43$ & $19.10 \pm 0.54$ & $41 \pm 5$ & 2086 \\
\hline & 100 & $25.98 \pm 0.85$ & $55.12 \pm 2.99$ & $11.81 \pm 0.31$ & $20.79 \pm 0.58$ & $43 \pm 2$ & 2294 \\
\hline & 200 & $7.67 \pm 0.60$ & $57.84 \pm 4.09$ & $7.00 \pm 0.53$ & $12.52 \pm 0.27$ & $22 \pm 4$ & 748 \\
\hline & 300 & $2.17 \pm 0.26$ & $56.54 \pm 6.61$ & $6.15 \pm 0.14$ & $10.83 \pm 0.18$ & $14 \pm 6$ & 310 \\
\hline & 400 & NS & NS & NS & NS & NS & NS \\
\hline & 500 & NS & NS & NS & NS & NS & NS \\
\hline SD & & 10.66 & 10.56 & 2.84 & 4.20 & 13.71 & \\
\hline $\mathrm{CV}$ & & 67.11 & 18.70 & 29.13 & 24.90 & 29.16 & \\
\hline
\end{tabular}

PRLA = Primary leaf; TLA = Terminal leaflet area; SDLH = Seedling height; PLHSW = Plant height at six weeks; NS = No survived plant; MSSPP = Mean seed setting per plant; AMSS = Amount of seed setting 
(b)

\begin{tabular}{|c|c|c|c|c|c|c|c|}
\hline Cowpea accession & Treatment dose (Gy) & PRLA $\left(\mathrm{cm}^{2}\right)$ & $\operatorname{TLA}\left(\mathrm{cm}^{2}\right)$ & SDLH (cm) & PLHSW (cm) & MSSPP & AMSS \\
\hline \multirow[t]{6}{*}{ IT86D-719 } & 0 & $19.55 \pm 0.71$ & $45.72 \pm 1.88$ & $11.22 \pm 0.21$ & $19.59 \pm 0.10$ & $35 \pm 6$ & 2265 \\
\hline & 100 & $19.68 \pm 0.86$ & $45.87 \pm 1.57$ & $11.29 \pm 0.25$ & $18.87 \pm 0.21$ & $37 \pm 7$ & 2285 \\
\hline & 200 & $18.51 \pm 1.03$ & $45.19 \pm 1.74$ & $10.23 \pm 0.22$ & $17.46 \pm 0.37$ & $27 \pm 2$ & 2105 \\
\hline & 300 & $11.83 \pm 1.06$ & $42.52 \pm 1.74$ & $6.93 \pm 0.40$ & $16.27 \pm 0.29$ & $20 \pm 5$ & 1713 \\
\hline & 400 & $6.63 \pm 0.99$ & $41.97 \pm 1.53$ & $5.28 \pm 0.27$ & $14.00 \pm 0.27$ & $16 \pm 6$ & 758 \\
\hline & 500 & $2.37 \pm 0.56$ & $44.29 \pm 1.55$ & $3.53 \pm 0.13$ & $11.14 \pm 0.71$ & $16 \pm 3$ & 750 \\
\hline SD & & 7.31 & 5.29 & 3.14 & 3.14 & 25.92 & \\
\hline $\mathrm{CV}$ & & 55.82 & 11.94 & 38.91 & 19.37 & 48.53 & \\
\hline \multirow[t]{6}{*}{ IT86D-1010 } & 0 & $22.06 \pm 1.06$ & $26.26 \pm 1.88$ & $8.51 \pm 0.23$ & $20.66 \pm 0.06$ & $38 \pm 6$ & 2002 \\
\hline & 100 & $21.91 \pm 0.72$ & $27.58 \pm 1.57$ & $8.66 \pm 0.17$ & $19.44 \pm 0.27$ & $40 \pm 2$ & 2210 \\
\hline & 200 & $15.76 \pm 1.13$ & $26.88 \pm 1.63$ & $8.18 \pm 0.20$ & $17.86 \pm 0.28$ & $25 \pm 5$ & 1550 \\
\hline & 300 & $11.18 \pm 0.82$ & $26.52 \pm 1.41$ & $6.26 \pm 0.25$ & $16.27 \pm 0.09$ & $17 \pm 8$ & 1120 \\
\hline & 400 & $6.61 \pm 1.22$ & $25.64 \pm 1.84$ & $5.94 \pm 0.21$ & $15.52 \pm 0.34$ & $13 \pm 4$ & 756 \\
\hline & 500 & $4.91 \pm 0.72$ & $27.14 \pm 1.44$ & $3.78 \pm 0.13$ & $14.74 \pm 0.25$ & $12 \pm 6$ & 749 \\
\hline SD & & 7.43 & 5.00 & 1.87 & 3.45 & 28.11 & \\
\hline $\mathrm{CV}$ & & 54.09 & 18.74 & 27.13 & 20.81 & 51.18 & \\
\hline \multirow[t]{6}{*}{ IT89KD-374-57 } & 0 & $26.69 \pm 1.24$ & $36.66 \pm 2.92$ & $7.86 \pm 0.19$ & $15.93 \pm 0.10$ & $33 \pm 3$ & 1990 \\
\hline & 100 & $26.81 \pm 1.06$ & $38.44 \pm 2.74$ & $7.88 \pm 0.22$ & $16.03 \pm 0.15$ & $35 \pm 5$ & 1856 \\
\hline & 200 & $19.79 \pm 0.87$ & $37.66 \pm 3.15$ & $7.45 \pm 0.16$ & $15.28 \pm 0.20$ & $26 \pm 3$ & 1761 \\
\hline & 300 & $12.68 \pm 0.85$ & $38.61 \pm 2.68$ & $6.96 \pm 0.17$ & $14.49 \pm 0.29$ & $23 \pm 6$ & 1520 \\
\hline & 400 & $6.9 \pm 0.80$ & $36.94 \pm 2.41$ & $5.91 \pm 0.19$ & $12.28 \pm 0.49$ & $18 \pm 2$ & 774 \\
\hline & 500 & $5.13 \pm 0.54$ & $36.99 \pm 2.92$ & $4.23 \pm 0.21$ & $10.27 \pm 0.46$ & $16 \pm 5$ & 758 \\
\hline SD & & 9.23 & 8.54 & 1.43 & 2.33 & 25.64 & \\
\hline $\mathrm{CV}$ & & 56.51 & 22.76 & 21.31 & 16.61 & 46.08 & \\
\hline \multirow[t]{6}{*}{ IT90K-284-2 } & 0 & $19.55 \pm 0.71$ & $48.48 \pm 3.92$ & $8.38 \pm 0.14$ & $19.77 \pm 0.32$ & $32 \pm 7$ & 1552 \\
\hline & 100 & $24.35 \pm 2.17$ & $51.03 \pm 3.06$ & $8.58 \pm 0.21$ & $20.58 \pm 0.32$ & $35 \pm 6$ & 1606 \\
\hline & 200 & $17.42 \pm 1.22$ & $48.62 \pm 3.98$ & $7.93 \pm 0.14$ & $19.00 \pm 0.28$ & $21 \pm 6$ & 1350 \\
\hline & 300 & $9.99 \pm 1.55$ & $48.95 \pm 2.20$ & $7.02 \pm 0.11$ & $16.60 \pm 0.36$ & $17 \pm 3$ & 1314 \\
\hline & 400 & $6.7 \pm 0.83$ & $42.55 \pm 3.10$ & $5.76 \pm 0.17$ & $14.28 \pm 0.39$ & $14 \pm 5$ & 755 \\
\hline & 500 & $4.24 \pm 0.96$ & $47.99 \pm 3.09$ & $4.23 \pm 0.19$ & $13.03 \pm 0.36$ & $12 \pm 4$ & 502 \\
\hline SD & & 9.36 & 10.26 & 1.64 & 3.02 & 19.85 & \\
\hline $\mathrm{CV}$ & & 63.44 & 21.40 & 23.55 & 17.55 & 39.14 & \\
\hline
\end{tabular}

PRLA = Primary leaf; TLA = Terminal leaflet area; SDLH = Seedling height; PLHSW = Plant height at six weeks; MSSPP = Mean seed setting per plant; AMSS = Amount of seed setting. 
Table 5. Seed set per $\mathrm{M}_{1}$ plant after optimal seed irradiation treatment $\left(\mathrm{LD}_{30-50}\right)$.

\begin{tabular}{|c|c|c|c|c|c|c|c|c|c|}
\hline Parameter & Dose & IB & IB-Y-1 & IB-CR & IB-BPC & IT86D-719 & IT86D-1010 & IT89KD-374-57 & IT90K-284-2 \\
\hline \multirow{3}{*}{$\begin{array}{l}\text { Seedling } \\
\text { survival }\end{array}$} & 0 & 43 & 36 & 44 & 41 & 35 & 38 & 33 & 32 \\
\hline & $\mathrm{LD}_{30}$ & 33 & 32 & 36 & 33 & 25 & 22 & 25 & 15 \\
\hline & $\mathrm{LD}_{50}$ & 24 & 24 & 27 & 25 & 20 & 11 & 20 & 4 \\
\hline \multicolumn{2}{|c|}{$\mathrm{M}_{1}$ (minimum recommended) } & 1000 & 1000 & 1000 & 1000 & 1000 & 1000 & 1000 & 1000 \\
\hline \multirow{2}{*}{$\mathrm{M}_{2}$} & $\mathrm{LD}_{30}$ & 22,084 & 22,131 & 24,923 & 22,268 & 13,895 & 11,396 & 12,950 & 8652 \\
\hline & $\mathrm{LD}_{50}$ & 9600 & 9720 & 11246 & 10125 & 6650 & 3141 & 5860 & 1428 \\
\hline
\end{tabular}

gamma irradiation mutagenesis for all the cowpea accessions used in this study showed definite trends which corroborate earlier findings. Generally, percentage seed germination and seedling survival were inversely related to radiation dosage. The higher the dose the lower the percentage seed germination and seedling survival in cowpea. Low germination of $\mathrm{M}_{1}$ seed has been attributed to genetic and physiological damage to embryo cells or tissues [18] [19], which can lead to abnormal cell division, cell death, mutation, tissue and organ failure and reduction of plant growth.

The results of the radio-sensitivity tests revealed a wide variation in the percentage seed germination and seedling survival for each of the radiation treatments among all the cowpea accessions studied (Figure 1 \& Figure 2). IB and its derivatives were more sensitive to gamma irradiation than the elite cultivars, which may be as a result of the genetic background of the accessions. Similar trend observed from the dosage effect curves (Figure 3 \& Figure 4) indicates that the elite cultivars were more radio-resistant due to their genetic composition. These results show that radio-sensitivity of cowpea to gamma radiation in terms of seed germination and seedling survival is genotype dependent.

The narrow range of $\mathrm{LD}_{50}$ shared by IB and its derivatives is probably a reflection of their relatedness and similar morphologies. The wide variation observed in the estimated $\mathrm{LD}_{50}$ among the eight cowpea accessions studied agrees with the reports of [10] who reported that $\mathrm{LD}_{50}$ of radio-susceptible cowpea cultivars Nakara and Shindimba was less than $200 \mathrm{~Gy}$ whereas the radio-resistance cultivar Bira exhibited $\mathrm{LD}_{50}$ above $600 \mathrm{~Gy}$. The observed variation in the $\mathrm{LD}_{50}$ among the cowpea genotypes was a result of the differences in their seed characteristics. Major factors determining radio-sensitivity are density and water, though the latter can be standardized by desiccation pre-treatment. This study further revealed that the absorbed radiation dosage is directly related to the surface texture of the seed coat (testa). Cowpea seeds with rough testa surface appeared to be radio-susceptible in comparison to cowpea with smooth testa surface which were relatively radio-resistant to gamma irradiation. This implies that lower ionizing radiation dosage is required to reach $\mathrm{LD}_{50}$ for seed germination and seedling survival in cowpeas with rough testa and vice versa. There appear to be a direct relationship between testa thickness of cowpea and the genotype susceptibility to gamma irradiation as shown by higher correlation found with germination and survival rates.

With respect to seedling morphological characteristics of the $\mathrm{M}_{1}$ plants, low gamma radiation treatment (100 Gy) increased the primary leaf area, terminal leaflet area, seedling height and plant height at six weeks in cowpea. There appeared to be some stimulating effect of gamma radiation up to $100 \mathrm{~Gy}$ on cowpea plant vigor. Similar observations were reported with low dose irradiation for doses up to $100 \mathrm{~Gy}$ of gamma irradiation on three cowpea cultivars [9] and up to $1.4 \times 10^{12}$ neutrons $/ \mathrm{cm}^{2}$ and $5000 \mathrm{r}$ X-ray significantly increased seedling height of southern-peas [20]. It was also reported that low radiation doses are accompanied by early emergence, increased percentage germination and field survival with healthy and vigorous seedlings [10]. This suggests that low gamma radiation treatment can be used to stimulate cowpea vegetative growth and plant vigor at $\mathrm{M}_{1}$ generation. However, the reduction in primary leaf area and seedling height as radiation treatments increased in all the cowpea accessions indicate that seedling vigor appeared to be inversely related to gamma dosage intensity above $100 \mathrm{~Gy}$. This is because the primary leaf area and seedling height determine the plant seedling vigor and survival. Doses of 200 Gy upward resulted in a marked reduction in the vigor of all cowpea accessions used in this study. One of the indices of plant vigor is plant height at six weeks. The observed plant height at six weeks across radiation treatments and cowpea genotypes shows that the vigor of $\mathrm{M}_{1}$ cowpea plants reduces with in- 
creasing radiation dosage. These results are consistent with earlier research reports in cowpea [9] [10], in soybeans [19], in rice [21], in long beans [22] and in tomato and okra [23]. However, radiation treatments did not appear to affect terminal leaflet area of cowpea plants at $\mathrm{M}_{1}$ generation.

Some negative consequences of radiation overdoses have been identified [24]; such as deletions of DNA nucleotide sequences that may cause reading-frame shifts, inactive protein products, or faulty transcripts. It therefore implies that seed treatment with gamma rays at higher doses has inhibitory effects on the vegetative growth of $\mathrm{M}_{1}$ plants. This is because ionizing radiation at higher levels is injurious to some enzymes and growth hormones [18] which may have contributed to the reduction in cell multiplication and growth in plants. Consequently, this contributed to the low amount of seeds harvested at higher radiation doses. This reduction in the amount of seed harvested at high radiation treatments in some accessions was not unexpected since there were very low plant survivals at those radiation treatments. This finding therefore implies that the lethal effect of high radiation doses would limit the number of $\mathrm{M}_{2}$ generation plants available for screening and beneficial mutant selection in certain genotypes of cowpea. In mutation induction radio-sensitivity is performed with the purpose of selecting the optimal treatment for a specific genotype, i.e. the dose $\mathrm{LD}_{30-50}$ that will provide the desired genotype (mutant trait in low mutational load genetic background) at a frequency that can be detected in a mutant population. This is especially important for restoration of an elite genetic background by back crossing. In all the cowpea accessions studied, the quantity of seeds harvested from $\mathrm{M}_{1}$ plants at maturity decreased with increasing radiation treatments. Less than 1000 seeds were obtained in the derivatives of IB at 200 and 300 Gy, whereas in cultivars IT86D-719, IT86D-1010, IT89KD-374-57 and IT90K-284-2 less than 1000 seeds were harvested at 400 and $500 \mathrm{~Gy}$. This reduction in the amount of $\mathrm{M}_{2}$ seed harvested was expected since there were very low plant survival rates at high radiation treatments in some accessions. This result indicates that very little amount of seeds would be available to raise the $\mathrm{M}_{2}$ plants in certain genotypes for some treatments as shown in the Table 5 . Base of the minimum bulk seed of 1000 recommended for mutation induction, elite cultivars recorded a reduced $\mathrm{M}_{2}$ population compared to the IB and its relative mutant lines. Therefore more than 1000 seeds are needed for the development of the mutant population for all genotypes especially for the elite cultivars.

Genetic variation may explain the differential responses of the 8 cowpea cultivars to gamma irradiation. The seed physical characteristic may help in the selection of dose or range of doses for radio-sensitivity test of cowpea (Vigna unguiculata).

As recommendation, the optimum seed irradiation treatments for mutation induction are given in Table 3; these vary according to seed characteristics. It is general practice to raise about 1000 individual $\mathrm{M}_{1}$ plants to provide range of mutants in the $\mathrm{M}_{2}$ population. The number of seeds required for irradiation, that will result in at least 1000 viable $\mathbf{M}_{2}$ plants is given in Table 5 .

\section{Conclusion}

Radio-sensitivity needs to be determined for each genotype prior to mutation induction. Mutagen and the plant material used in the mutagenesis treatment are key factors for the successful improvement of crop species through induced mutation. Genotypic variation was observed with respect to radio-sensitivity based on the differences between treated and untreated seed through germination and survival rates. The biomass assessment also showed the efficiency of gamma irradiation in cowpea mutagenesis. This study has revealed that the susceptibility of cowpea to gamma irradiation is more associated with the texture and thickness of the seed testa than mean seed weight. The results corroborated the genetic variation of IB, its relatives and elite cultivars with their response to gamma irradiation. This finding should be taken into consideration for cowpea mutagenesis.

\section{Acknowledgements}

We thank the International Atomic Energy Agency for the provision of gamma irradiation services.

\section{Competing Interests}

The authors have no conflict of interest related to the work described in this manuscript.

\section{References}

[1] Singh, B.B. (2012) Breeding Diverse, Durable, and Diet-Plus Cowpea Varieties for Increased Cowpea Production and 
Enhanced Nutrition and Health in the $21^{\text {st }}$ Century. In: Boukar, O., Coulibaly, O., Fatokun, C.A., Lopez, K. and Tamo, M., Eds., Innovative Research along the Cowpea Value Chain. Proceedings of the Fifth World Cowpea Conference on Improving Livelihoods in the Cowpea Value Chain through Advancement in Science, Saly, 27 September-1 October 2010, International Institute of Tropical Agriculture (IITA), Ibadan, 17-29.

[2] Oyenuga, V.A. (1967) Agriculture in Nigeria. FAO Rome.

[3] Amjad, I., Iqtidar, A.K., Muhammad, S.K. and Nadia, A. (2006) Nutritional Quality of Important Food Legumes. Food Chemistry, 97, 331-335. http://dx.doi.org/10.1016/j.foodchem.2005.05.011

[4] FAO, Food and Agricultural Organization Statistical Production Report on Dry Cowpea in 2013. Published by FAO; 2015. Accessed 16/08/2015. http://faostat3.fao.org/download/Q/QC/E

[5] Rachie, K.O. (1985) Introduction. In: Singh, S.R. and Rachie, K.O., Eds., Cowpea Research, Production and Utilization, John Wiley and Sons Ltd., xxi-xxviii.

[6] Widders, I.E. (2012) Cowpea: A Solution to Global Challenges. In: Boukar, O., Coulibaly, O., Fatokun, C.A., Lopez, K. and Tamo, M., Eds., Innovative Research along the Cowpea Value Chain. Proceedings of the Fifth World Cowpea Conference on Improving Livelihoods in the Cowpea Value Chain through Advancement in Science, Saly, 27 September-1 October 2010, International Institute of Tropical Agriculture (IITA), Ibadan, xi-xviii.

[7] Bado, S., Forster, B.P., Nielen, S., Ghanim, A., Lagoda, P.J.L., Till, B.J. and Laimer, M. (2015) Plant Mutation Breeding: Current Progress and Future Assessment. Plant Breeding Reviews, 39, $23-88$. http://dx.doi.org/10.1002/9781119107743.ch02

[8] Osanyinpeju, A.O and Odeigah, P.G.C. (1998) Variation in Seed Proteins from Mutagen-Treated Cultivars and Selected Lines of Vigna unguiculata (L.) Walp. Plant Breeding, 177, 361-365. http://dx.doi.org/10.1111/j.1439-0523.1998.tb01954.x

[9] Ogidi, E.G.O., Omosun, G., Markson, A.A. and Kalu, M. (2010) Effects of Gamma Ray Irradiation on the Metric Traits of Vegetable Cowpea (Vigna unguiculata (L.) walp) in Umudike Southern Nigeria. Asian Journal of Science and Technology, 5, 86-90

[10] Horn, L. and Shimelis, H. (2013) Radio-Sensitivity of Selected Cowpea (Vigna unguiculata) Genotypes to Varying Gamma Irradiation Doses. Scientific Research Essays, 8, 1991-1997.

[11] Kharkwal, M.C. and Shu, Q.Y. (2009) The Role of Induced Mutations in World Food Secuity. In: Shu, G.Y., Ed., Induced Plant Mutations in the Genomics Era, Food and Agriculture Organization of the United Nations, Rome, 33-38.

[12] Micke, B., Donini, B. and Maluszynski, M. (1990) Induced Mutation for Crop Improvement. Mutation Breeding Review, No. 7, 1-4.

[13] Mba, C., Afza, R. and Shu, Q.Y. (2012) Mutagenic Radiations: X-Rays, Ionizing Particles, and Ultraviolet. In: Shu, Q.Y., Forster, B.P. and Nakagawa, H., Eds., Plant Mutation Breeding and Biotechnology, Joint FAO/IAEA Division of nuclear Techniques in Food and Agriculture International Atomic Energy Agency, Vienna, 83-90. http://dx.doi.org/10.1079/9781780640853.0083

[14] Sikora, P., Chawade, A., Larsson, M., Olsson, J. and Olsson, O. (2011) Mutagenesis as a Tool in Plant Genetics, Functional Genomics and Breeding. International Journal of Plant Genomics, 2011, Article ID: 314829. http://dx.doi.org/10.1155/2011/314829

[15] http://microbiologyon-line.blogspot.com/2009/09/ionizing-radiation-radiation.html

[16] Kodym, A., Afza, R., Forster, B.P., Ukai, Y., Nakagawa, H. and Mba, C. (2012) Methodology for Physical and Chemical Mutagenic Treatments. In: Shu, Q.Y., Forster, B.P. and Nakagawa, H., Eds., Plant Mutation Breeding and Biotechnology, Joint FAO/IAEA Division of nuclear Techniques in Food and Agriculture International Atomic Energy Agency, Vienna, 169-180. http://dx.doi.org/10.1079/9781780640853.0169

[17] Sparrow, A.H. (1961) Types of Ionizing Radiation and Their Cytogenetic Effects. Symposium on Mutation and Plant Breeding, Cornell University, Ithaca, 28 November-2 December 1960, National Academy of Sciences Council Publication, Washington DC, 891, 55-119.

[18] Lagoda, P.J.I. (2012) Effects of Radiation on Living Cells and Plants. In: Shu, Q.Y., Forster, B.P. and Nakagawa, H., Eds., Plant Mutation Breeding and Biotechnology, Joint FAO/IAEA Division of nuclear Techniques in Food and Agriculture International Atomic Energy Agency, Vienna, 123-134. http://dx.doi.org/10.1079/9781780640853.0123

[19] Mudibu, J., Kalonji-Mbuyi, A., Kizungu, R.V. and Nkongolo, K.K.C. (2012) Effect of Gamma Irradiation on Morpho-Agronomic Characteristics of Soybeans (Glycine max L.). American Journal of Plant Sciences, 3, 331-337. http://dx.doi.org/10.4236/ajps.2012.33039

[20] Jones, S.T. (1965) Radiation-Induced Mutations in Southern Peas. The Journal of Heredity, 56, 273-276.

[21] Harding, S.S., Dixon, C.A., Johnson, S.D., Taylor, D.R. and Turay, M.Y. (2012) Effect of Gamma Rays on Seed Germination, Seedling Height, Survival Percentage and Tiller Production in Some Rice Varieties Cultivated in Sierra 
Leone. American Journal of Experimental Agriculture, 2, 247-255.

[22] Kon, E., Ahmed, O.H., Hussain, N.M. and Saamin, S.A. (2007) Gamma Radiosensivity Study in Long Bean (Vigna ses-quipedalis). American Journal of Applied Sciences, 4, 1090-1093. http://dx.doi.org/10.3844/ajassp.2007.1090.1093

[23] Norfadzrin, F., Ahmed, O.H., Rahman, D.A. and Shaharudin, S. (2007) A Preliminary Study on Gamma Radiosensitivity of Tomato (Lycopersicon esculentum) and Okra (Abelmoschus esculentus). International Journal of Agricultural Research, 2, 620-625. http://dx.doi.org/10.3923/ijar.2007.620.625

[24] Brown, N. (2013) Mutagenesis. Institution of Plant Breeding, Genetics and Genomics, University of Georgia. http://plantbreeding.coe.uga.edu/index.php?title=20._Mutagenesis 